\section{GlaxoSmithKline pushes its labs towards 'biotech' future}

\section{David Adam, London}

One of the world's largest drug corporations, GlaxoSmithKline, has announced radical plans to rearrange its research laboratories into six units that, it says, will each walk, talk and look like individual biotechnology businesses.

But some of the 16,000 researchers at the company, which was founded last December by the merger of GlaxoWellcome and SmithKline Beecham, are already expressing doubts that the shake-up will have the desired effect. They are dubious about how much autonomy the research units will be allowed, and warn about the impact on staff morale of post-merger jockeying for position.

GlaxoSmithKline says that the new units will operate as internal, competing biotech businesses. Its chief executive, Jean-Pierre Garnier, argues that the units are the best way to turn ideas into new drugs. "To take a target and transform it into a product that works in the clinic, you have to be nimble," he says.

The autonomous units will take validated drug targets, investigate dose and delivery methods, and then test how safe and effective they are in animals. The units will also help to carry out the initial stages of human tests but will then hand over responsibility to the core company for large-scale, expensive clinical trials.

Garnier adds that the earlier stages in the drug-discovery process, including research in functional genomics and high-throughput screening of therapy candidates, will continue to be a large operation, integrated across several of the newly merged company's sites. "We start big, we move to small and then back to big again," he says. "Nobody has ever tried to do this before."

Three of the new drug-discovery centres, which will compete among themselves for company resources, will be located in the United States, two in Britain and one in Italy. The company's laboratory in Upper Providence, Pennsylvania, will work on anti-infective medicines; Upper Merion, Pennsylvania will tackle cardiovascular, oncology and genitourinary conditions; and research into metabolic control and antivirals will be based at Research Triangle Park, North Carolina.

In Europe, researchers in Verona will develop psychiatry drugs leads; neurology drug candidates will be investigated at Harlow; and the Stevenage site will handle anti-inflammatory research. There will be a separate division for vaccines.

"The people in the centres will be rewarded strictly on what they produce and the scientists behind them will be very account-

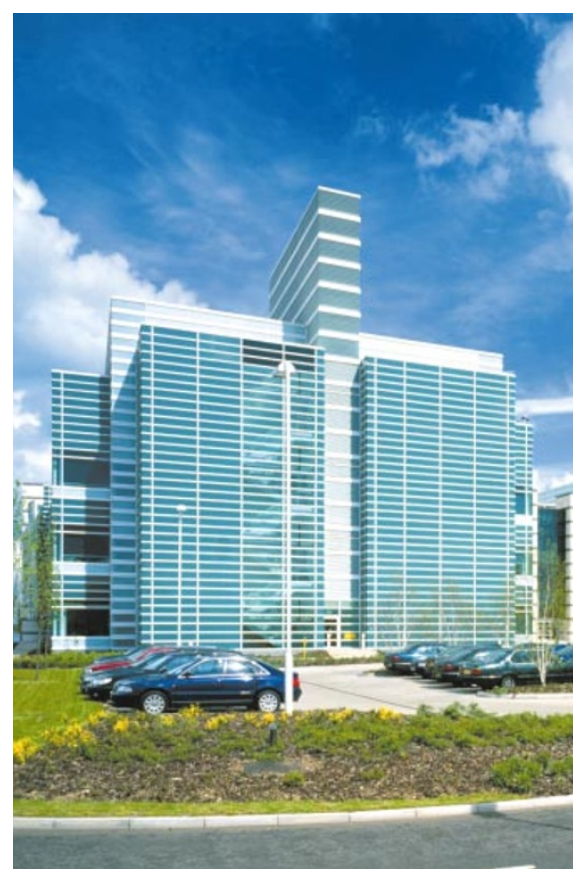

Rapid response: GlaxoSmithKline's Harlow laboratory is gearing up for autonomy.

able. They can't hide and will have to produce drugs," Garnier insists.

The move to create the units follows the trial isolation of SmithKline Beecham's antibiotic and antiviral research activities. "It helped people to move faster and now we want to do it on a much bigger scale," Garnier says. "We are pretty certain it's going to work."

Tadataka Yamada, head of research at GlaxoSmithKline, says the changes will introduce a range of incentives to mimic the workings of biotech companies, including stock options, royalties on drug sales, and bonuses for both groups and individuals. Yamada also promises "high-profile recognition within the company" for existing and emerging stars.

But the company has already announced that two research centres will close and more could follow, and some GlaxoSmithKline researchers are expressing concerns about the integration plans. Several employees said privately that they are uncertain about how well the units will work. They warn that the large gravitational pull of the central corporation will continue to dominate the trajectories of the smaller research units orbiting it.

Some of the researchers also noted that a previously successful Glaxo drug-discovery unit, based on a similarly entrepreneurial model and located within the pharmacology department at the University of Cambridge, is being closed by the merged corporation. http://www.gsk.com

\section{Hepatitis pioneer takes the reins for French medicine}

Declan Butler, Paris

Christian Bréchot, a clinical researcher specializing in liver disease and hepatitis, has been named as the new director of INSERM, France's main biomedical research agency.

Bréchot is best known for his work on hepatitis B and C - especially his investigation of the role of viral hepatitis in the development of liver cancer (see Nature 286, 533-535; 1980).

After his appointment, Bréchot said in a newspaper interview that one of his priorities would be to strike the right balance between clinical and basic research at INSERM. He also plans to develop informal research groups within the agency to act as special "strike forces" in important areas of multidisciplinary research. And he says he will rejuvenate INSERM from the bottom up, by supporting talented young researchers.

Bréchot's appointment was announced last week by Roger-Gérard Schwartzenberg, the French research minister. Schwartzenberg says he wants Bréchot to give priority to emerging areas of research such as gene therapy, and to areas of new relevance to public health, such as the study of prion-related diseases.

The research minister also wants to see better coordination between INSERM's 256 research units, and more cooperation with other research sponsors in France.

Bréchot's dual role as a practising clinician, at the Necker Children's Hospital in Paris, and as a researcher he is director of an INSERM unit at the Pasteur Institute - apparently contributed to his selection by Schwartzenberg. "It is important to have someone who has direct and regular contact with patients," says the minister.

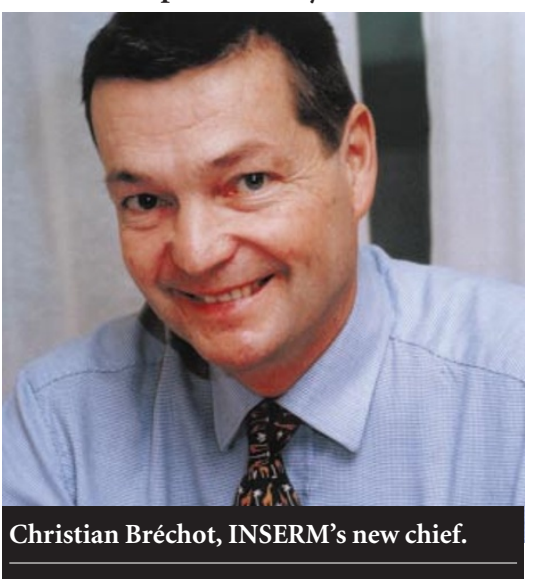

